\title{
POR QUE O TRABALHO E NÃO ANTES A ARTE?
}

\author{
Roberto Rondon (1)
}

Gostaria de começar esse texto com uma pergunta: "Por que o trabalho e não antes a arte?"

Que mágica foi essa que encantou os homens e mulheres de nossa sociedade a partir do final do século XIX, justamente quando os processos de reprodução da vida alcançaram tal grau que a produção mundial tornou-se suficiente para atender a necessidade global com sobra?

Foi justamente a partir daquele momento - e hoje mais do que nunca - quando todas as condições materiais para a implantação do reino da liberdade estavam postas, que a lógica da necessidade se impôs de maneira universal.

Como afirmava Paul Lafargue,

"Uma estranha loucura se apossou das classes operárias das nações onde reina a civilização capitalista. Esta loucura arrasta consigo misérias individuais e sociais que há dois séculos torturam a triste humanidade. Esta loucura é o amor ao trabalho, a paixão moribunda do trabalho, levado até ao esgotamento das forças vitais do indivíduo e da sua progenitora. Em vez de reagir contra esta aberração mental, os padres, os economistas, os moralistas sacrossantificaram o trabalho. Homens cegos e limitados, quiseram ser mais sábios do que o seu Deus; homens fracos e desprezíveis, quiseram reabilitar aquilo que o seu Deus amaldiçoara. Eu, que não confesso ser cristão, economista e moralista, recuso admitir os seus juízos como os do seu Deus; recuso admitir os sermões da sua moral religiosa, econômica, livrepensadora, face às terríveis conseqüências do trabalho na sociedade capitalista." (LAFARGUE, s/d)

Se o objetivo desse ensaio - e desse encontro - é abordar a filosofia e a arte na educação como resistência é preciso apontar os fenômenos aos quais devemos resistir.

Se as "instituições próprias do ensino" nasceram como "Scholé" (2), isto é, local do ócio, como pudemos transformá-la em local do negócio, do trabalho, do "bussiness".

Nossa LDB anuncia no seu "Título I", intitulado "Da Educação", em seu parágrafo 2o que, "a educação escolar deverá vincular-se ao mundo do trabalho e à prática social".

Nenhuma palavra sobre a arte. $\mathrm{O}$ vinculo da educação deve ser estabelecido com o trabalho e a prática social, que cada vez mais fomentada nas relações do trabalho e do mercado.

Mas, volta a pergunta: "Por que o trabalho e não antes a arte?" 
O novo ministério da educação anunciou uma proposta de reformulação do ensino médio onde a vinculação deste com o ensino técnico profissionalizante é defendida arduamente. A proposta, apesar de alertar para os perigos do ensino técnico transformar-se em um adestramento para o mercado, propõe em sua introdução que:

"a educação profissional e tecnológica, em termos universais, e, no Brasil, em particular, reveste-se cada vez mais de importância como elemento estratégico para a construção da cidadania e para melhor inserção de jovens e trabalhadores na sociedade contemporânea, plena de grandes transformações e marcadamente tecnológica." (Propostas de política públicas para a educação profissional e tecnológica, 2003, 11)

Mais adiante define, com todas as letras que "é oportuno recuperar o papel fundamental do ensino médio, qual seja, o de estabelecer a relação entre conhecimento e prática de trabalho."(Propostas de política públicas para a educação profissional e tecnológica, 2003, 17)

O que a LDB anuncia como uma possibilidade, o governo de esquerda transforma em necessidade

Mas, diante de tal ênfase, volta a pergunta: "Por que o trabalho e não antes a arte?"

Cabe então nesse momento, antes de falarmos na arte, refletir um pouco sobre esse momento que coloca o trabalho como princípio formativo e tábua de salvação da humanidade.

Em todos os cantos do país se ouvem nas filas dos desesperados: "Mais trabalho, mais trabalho!"

Os principais candidatos à presidência do Brasil em 2002 apregoavam aos quatro ventos a criação de 8 ou 10 milhões de empregos, associadas a uma expansão do mercado como tábuas de salvação para a nação.

Não importa qual, para que e em quais condições, apenas "mais trabalho", pois através dele se espera recuperar não as condições de sobrevivência material - pois com os salários e as jornadas da massa dos trabalhadores brasileiros essa afirmação seria falaciosa - mas as condições de dignidade. Portar uma vassoura pelas ruas; balançar bandeirinhas nas estradas; sentar-se em frente ao telefone ou ao computador nos escritórios; carregar caixas nos supermercados e feiras; operar máquinas nas fábricas, dirigir ônibus ou automóveis pelas congestionadas ruas das metrópoles; participar de reuniões infindáveis; assinar papéis; dar 30 ou 40 horas de aula por semana para classes de 100 alunos; teclar lap tops, decidindo sobre a vida e a morte de milhares de pessoas; enfim, tudo isso dá dignidade aos homens $e$ mulheres na ensandecida moral da sociedade contemporânea.

Segundo um dos profetas do capitalismo Adam Smith, "a mente da maioria dos homens, desenvolve-se necessariamente de e por suas ocupações costumeiras". Diante dessa afirmação poderíamos nos perguntar qual o desenvolvimento possível 
da "mente" de uma caixa de supermercado que passa oito, nove ou dez horas por dia de sua vida a passar o leitor magnético nas mercadorias, ou de um jovem especulador a comprar e vender ações na bolsa...

Qual a sensibilidade ("aesthesis") e erotismo, elementos fundamentais para a formação humana, são desenvolvidos nessas atividades?

Nesse quadro de elogio ao trabalho, seria importante darmos um salto ao passado e olharmos a origem da sociedade capitalista, principalmente no início da industrialização nos séculos XVIII e XIX, onde veremos que a grande dificuldade da burguesia era arregimentar trabalhadores dentro dessa nova lógica do trabalho industrial e discipliná-los na nova ordem longe dos prazeres, da arte, da sexualidade e dos jogos.

Não que busquemos aqui recompor uma imagem idílica ou do "paraíso perdido" como afirma Thompson, da sociedade pré-industrial, mas sim verificar algumas paisagens das cruéis origens do capitalismo moderno, tentando compreender como aquilo que um dia foi considerado como a verdadeira danação da humanidade, transformou-se em seu princípio formativo, em detrimento das outras dimensões da vida como a arte e os prazeres que passara para a esfera do supérfluo.

A tese central de muitos estudiosos é de que a disciplina foi a mais importante conquista do capitalismo e seu fundamento. Como afirma Pollard, "em muitos aspectos, a direção racional e metódica da mão de obra foi o problema essencial de direção da Revolução Industrial e o que exigiu a mais violenta ruptura com o passado".(POLLARD, 1987, 217)

Os trabalhadores artesanais da Europa resistiram arduamente a se empregarem nas fábricas nascentes que eram associadas no imaginário da época aos presídios e casas de correção, tanto assim que a primeira mão de obra das fábricas vinha justamente dos reclusos e dos órfãos, cujas casas eram conhecidas como work houses.

"Os pensamentos dos primeiros empresários, que buscavam uma mão de obra dócil de novo tipo, se dirigiram de modo natural à mão de obra não livre, tanto na Grã Bretanha como no continente. Tampouco foram totalmente inconexos os esforços complementares para converter os asilos para pobres em fábricas-asilo, já que os objetivos de ver castigados e educados para o trabalho aos desocupados e reduzir o número de pobres foram compartilhados pelas classes patronais em todas as partes".(idem, 221).

Castigos físicos e punições financeiras, como pesadas multas e descontos, foram utilizados abertamente como forma de adequar o trabalhador aos horários fixos, pontualidade, economia de tempo e jornadas contínuas, num "ascetismo forçado", que visava gerar uma nova ética do trabalho como valor positivo. 
Foram desenvolvidas várias campanhas contra o ócio aos sábados e domingos, além de um forte ataque à bebida $e$ às festas tradicionais. Essas atividades dominicais passavam a ser tida como fontes de desvio, vício e pecado.

Por isso "em quase todas as partes, os empresários mantiveram igrejas, capelas e escolas dominicais, tanto para fomentar a educação moral no sentido mais habitual do termo como para inculcar a obediência".(ibidem, 258). Trabalho e educação começam a se tornar aliados na tarefa de preparar os novos membros desse modelo civilizatório que transformou, nas palavras de Weber, o trabalhador em seu próprio feitor.

Se atravessarmos o Atlântico e observarmos o desenvolvimento dessas relações no Brasil, teremos um agravante. De nossa fundação ate o século XIX, todo o discurso e a pratica do trabalho o colocava como uma atividade inferior, destinada aos escravos (3) e para alguns homens livres, brasileiros não nobres, que perambulavam pelo país dedicando-se principalmente ao comercio e a agricultura.

Na segunda metade do século XIX com a pressão política e econômica internacional pelo fim do trabalho escravo, a burguesia agrária brasileira viu-se as voltas com o problema de uma nova construção nas relações de trabalho.

\section{Como afirma SALLLES:}

"há que se considerar que nos limites da sociedade brasileira, habituada a relação entre o senhor e o escravo, tornava-se extremamente difícil o aparecimento de um trabalhador que considerasse, de modo positivo, o ato produtivo como condição de liberdade. Daí a opção imigrantista ter sido definitiva quando se tornou impositivo substituir o escravo e criar um mercado de mão-de-obra livre".(1986,39)

Isso levou a um reordenamento de todo discurso sobre o trabalho pelos republicanos e liberais, que organizaram posteriormente um novo ordenamento jurídico e social no país.

"O trabalho, por ser condição para a ampliação e reprodução do capital, precisava ter sua noção ideológica redimensionada. Em decorrência disso, ele aparece no discurso republicano com o poder de criar a riqueza. $\mathrm{O}$ trabalho e compreendido pelo pensamento liberal como condição intrínseca ao homem que, ao se desenvolver, possibilita a criação dos bens morais, pois recupera e eleva o sentido ético dos indivíduos e dos bens materiais. A acumulação desses bens morais $e$ materiais forma o cabedal de uma nação."(idem, 42)

De atividade aviltante e degradante, o trabalho passa ser o fundamento do progresso e da civilização, portanto enobrecedor.

"Nesta perspectiva teórica, o trabalho adquire os qualificativos de construtor do progresso, logo, da riqueza. Decorre daí a preocupação com a profissionalização como meio para tornar os homens mais habilitados para as atividades produtivas. Estes homens aptos a uma maior produtividade promoveram o enriquecimento do 
Estado, e criariam também para si as possibilidades e condições de enriquecimento".(ibidem,130)

Obviamente que nos albores de nossa época este novo discurso e marcado pela divisão de classes, isto $e$, a quem se destina o trabalho e sua disciplina são os pobres. Para os membros da elite são reservados os saberes científicos, artísticos e filosóficos, para os restantes um ensino que visava o mundo dos ofícios e do disciplinamento.

Diversas organizações sociais como a maçonaria, as sociedades de divulgação das ciências e as próprias Igrejas católica e protestante organizam escolas para os pobres visando, através do trabalho, inculcar-lhes a civilização, a ordem e o progresso.

Métodos como os de Lancaster e do ensino mútuo eram defendidos pelos educadores liberais como contrapontos à tradicional educação jesuíta e inserir os novos trabalhadores na ordem social nascente.

Como afirma LINS,

"O método Lancaster irá representar no século XIX uma proposta redentora da classe operária, para os setores da produção que carecem de um operariado dócil, disciplinado e que possuam os conhecimentos rudimentares da leitura escrita $e$ aritmética."(LINS, 1999, 78)

No mesmo sentido a obra do Barão de Gérando, Cours Normal, sobre o ensino mutuo, adotado na França desde 1815, foi traduzido no Brasil, por ordem do "decreto no. 28 de 1839, para que fosse usado pelos professores de primeiras letras." (BASTOS, 1999, 251).

Entre tantas pérolas o principal mote do método é a ordem que "é o sinal que atesta a presença da inteligência". (idem, 247)

Para os mestres que irão ensinar as classes trabalhadoras da sociedade ele alerta para o fato que:

"Os indivíduos das classes laboriosas têm pouco tempo para se aplicarem a conhecimentos teóricos e poucas ocasiões de usar deles. Só a educação pode preservar ou da pobreza ou do vício a quem não tem recursos mais que os braços. Será condenado a privações, e a educação o acostumará a resignar-se sem queixume; terá de fazer grandes esforços; de continuar com perseverança; ela lhe dará valor e ânimo; ela o defenderá; ela o ensinará a tirar recursos de si mesmos; ela lhe dará a necessária energia para superar obstáculos; ela lhe tornará fácil à economia pelos hábitos de ordem e temperança; ela lhe ensinará a estar contente com a situação que lhe coube de quinhão." (ibidem, 258)

Apesar dessas considerações conservarem várias crenças presentes até hoje, a crueza frente ao papel da educação dos trabalhadores, por outro ela não oculta, 
como os discursos atuais, que a vida dedicada ao trabalho é sofrimento que inferioriza o individuo a que a ele se dedica.

Nesse mesmo período deu-se o nascimento das duas primeiras faculdades brasileiras em São Paulo e Pernambuco. Fundadas para formar a elite dirigente do país, elas possibilitaram a formação de várias gerações de filósofos, poetas e artistas.

Nos relatos de seus alunos podemos enxergar a diferença com as concepções anteriormente citadas, onde o trabalho é o princípio formador. Aqui vão longe quaisquer preocupações com a atividade produtiva como relata José de Alencar em suas memórias do tempo de estudante.

"Os dois primeiros anos que passei em São Paulo foram para mim de contemplação e recolhimento de espírito. Assistia retraído ao bulício acadêmico e familiarizado de perto com esse viver original, inteiramente desconhecido para mim, que nunca fora pensionista de colégio nem havia até então deixado o regaço da família. As palestras à mesa de chá; as noites de conversa até o romper da alva entre a fumaça dos cigarros; as anedotas e as aventuras da vida acadêmica sempre repetidas; as poesias clássicas da literatura paulistana e as cantigas tradicionais do povo estudante; tudo isto sugava o meu espírito adolescente, como a tenra planta que absorve a linfa para mais tarde desabrochar a talvez pálida florzinha. Depois vêm os discursos recitados nas solenidades escolares, alguma nova poesia de Otaviano, os brilhos do banquete de estudantes; o aparecimento de alguma obra recentemente publicada; $e$ outras novidades literárias que agitavam a rotina do nosso viver habitual e comoviam um instante a colônia acadêmica." (ALENCAR, in VENÂNCIO FILHO, 1982, 147)

Bem, o tempo passou desde então. O capitalismo e seu modelo civilizatório se impuseram por todo o mundo. Junto com ele houve o desenrolar das relações de trabalho e educacionais e o que assistimos não foi a sua humanização, mas o coroamento do princípio da necessidade.

Na encruzilhada entre uma formação para a liberdade possível ou para a repressão optou-se pela última.

A universidade que nasce como a divulgadora das artes liberais, onde seriam "ensinados os elementos da ciência, belas artes e artes"(VENÂNCIO FILHO, 1982, 19), chega ao momento atual tendo como principio formativo seu oposto, o trabalho.

Acompanhando a essa ordenação, as novas instituições de ensino superior que nasceram e/ou se expandiram após a nova LDB se caracterizam por sua operacionalidade e busca pela adaptação ao mercado, reduzindo seu papel ao adestramento e treinamento de mão de obra e, nos casos mais avançados, ao desenvolvimento de pesquisas para a iniciativa privada. "Educação para o Mercado"; "Formando vencedores"; "A Universidade que lhe garante o sucesso", são alguns dos "slogans" que podem ser vistos nos outdoors das cidades brasileiras 
e que explicitam esse novo momento. O ensino superior público, por sua vez, é tomado pelas empresas junior, pelas parcerias universidade-empresa, pelo CIEE, pelo SEBRAE, pelos programas trainee, levando a uma situação que discutiremos um pouco mais adiante.

Esse processo gerou a sobrevalorização das carreiras tecnológicas e a desqualificação dos cursos como artes e filosofia, para as quais no máximo se escutam comentários como: "Nossa, que bonito!", seguido pelo bordão: "mas para que serve?". Para mantê-las atraentes ao novo público, várias instituições tentam adequar esses cursos à demanda do mercado,. Adaptando seus currículos e criando novas habilitações como "Pedagogia nas empresas", "Design"; "Filosofia na Escola"; imprimem esforços nos manuais dos vestibulandos para mostrar qual a possibilidade de atuação, isto é, trabalho, para os que vierem a ingressar nesses cursos; adequai suas exigências à "realidade" dos alunos que, "coitados", trabalham e não tem tempo para estudar, nunca pensando em enfrentar essa situação $e$ adequar o mundo do trabalho à necessidade da formação. Enfim, todas as transformações que tem transformado a universidade brasileira numa grande indústria.

Mas, por que o trabalho e não antes a arte?

Como falar em poesia e musica com o crescente desemprego e, sua contraface, jornadas de trabalho cada vez maiores e mais intensas.

Como dizer que temos tempo para fruir as experiências estéticas e eróticas, quando o que se valoriza são frases como: "estou correndo"; "vou lutando"; "não dá tempo"; e outras pérolas que resumem a vida humana no que diz o grupo punk "Molotov Cocktail" na canção Invisible Cell: "Work, eat, sleep, death!".

Se a arte autêntica, desde o romantismo, buscou se constituir com autonomia e liberdade, no enfrentamento das determinações sociais e econômicas, podemos afirmar que ela se torna cada vez mais difícil.

Mas, talvez encontremos uma pista nas considerações de Herbert Marcuse quando afirmava que num mundo dominado pela lógica da necessidade e da repressão, "a arte desafia o princípio da razão dominante; ao representar a ordem da sensualidade, invoca uma lógica tabu - a lógica da gratificação, contra a da repressão." (MARCUSE, 1968, 165)

Nesse pequeno devaneio que aqui tentamos elaborar o que questionamos é uma face mais profunda de nossa organização social. Se o modelo de organização social que construímos a partir da Revolução Industrial nos ofereceu a promessa da liberdade, ao mesmo tempo nos colocou numa situação que Schiller já prenunciava no século XVIII, um mundo onde

"A fruição do prazer está separado do trabalho, os meios do fim, o esforço da recompensa. Eternamente acorrentado a um único e diminuto fragmento do todo, o homem configura-se apenas como um fragmento do todo, escutando sempre e 
apenas o monótono rodopiar da roda que ele faz girar; jamais desenvolve a harmonia do seu próprio ser e, em vez de dar forma à humanidade que existe em sua natureza, converte-se em simples marca de sua ocupação, de sua ciência." (SCHILLER, in MARCUSE, 1968, 166)

Insistir enquanto educadores, na substituição do trabalho pela arte como principio formador é transgredir o atual estado de miséria a que chegamos. É dar aos seres humanos a possibilidade de, libertos da necessidade, constituírem-se plenamente em todas as dimensões possíveis e utópicas. Não que a arte (ou a educação) tenha por si só o poder transformador desse estado de coisas, pois isso é uma atividade política, mas "a arte, com toda sua forma afirmativa, formaria parte do poder liberador do negativo e serviria para liberar o inconsciente e a consciência, ambos mutilizados, que reforçam as Instituições repressivas. (MARCUSE, 1970, 195)

Educar pela e para a arte é libertar o impulso lúdico que tem "por objetivo a beleza e por finalidade a liberdade." (MARCUSE, 1968, 166)

\section{BIBLIOGRAFIA}

BASTOS, Maria Helena Câmara. "A formação de professores para o ensino mútuo no Brasil: O curso normal para professores de primeiras letras do Barão de Gerando (1839). In: BASTOS, Maria Helena Câmara e FARIA FILHO, Luciano Mendes (orgs.). A escola elementar no século XIX: o método monitorial/mútuo. Passo Fundo: EDIUPF, 1999.

GRAZIA, Sebastian. Tiempo, trabajo y ócio. Trad. Consuelo Vazquez de Parga. Madrid: Tecnos, 1966.

LINS, Ana Maria Moura. "O método Lancaster: educação elementar ou adestramento." In:

BASTOS, Maria Helena Câmara e FARIA FILHO, Luciano Mendes (orgs.). A escola elementar no século XIX: o método monitorial/mútuo. Passo Fundo: EDIUPF, 1999.

LAFARGUE. Paul. Direito à preguiça. www.culturabrasil.pro.br/diretoapreguica.htm MARCUSE, Herbert. Eros e civilização. Trad. Álvaro Cabral. Zahar: Rio de Janeiro, 1968.

$$
\text { . "El arte em la sociedad unidimensional". In: La sociedad }
$$

opresora. Trad. Ítalo Manzi. Caracas: Tiempo Nuevo, 1970.

MARGLIN, Stephen. "Origem e funções do parcelamento das tarefas - para que servem os patrões." In; GORZ, André. Crítica da divisão do trabalho. Trad. Estela dos Santos Abreu. São Paulo: Martins Fontes, 1980. 
Propostas de política públicas para a educação profissional e tecnológica www.mec.gov.br/semtec, 2003.

POLLARD, Sidney. La gênesis de la direccion de empresa moderna: estúdio sobre la revolucion industrial em Gran Bretaña. Madrid: Ministerio do Trabajo y Seguridad Social, 1987.

SALLES, Iraci Galvão. Trabalho, progresso e a sociedade civilizada. São Paulo: Hucitec, 1986.

THOMPSON, E. P. A formação da classe operária inglesa: a maldição de Adão. Trad. Renato Busato Netto e Cláudia Rocha de Almeida. Rio de Janeiro: Zahar, 1987.

VENÂNCIO FILHO, Alberto. Das arcadas ao bacharelismo. São Paulo: Perspectiva, 1982.

(1) Bolsista do Programa de Pós Graduação em Educação da Universidade Federal de São Carlos. Bolsista da CAPES.

(2) Para essa discussão ver a obra de Sebastian Grazia citada na bibliografia.

(3) Não vão longe os discursos que narravam a história dos índios como indolentes e incapazes para o trabalho necessário para o desenvolvimento do país, que marcam até hoje o imaginário social sobre esses povos. 